\section{Nature: the many benefits of ecosystem services}

\begin{abstract}
SIR - In his Commentary "Selling out on
\end{abstract} nature" (Nature 443, 27-28; 2006), Douglas J. MoCauley dismisses the importance of ecosystem services as a tool in conservation and resource management. The author correctly notes that market-based approaches to conservation are no panacea, as has also been concluded by the Millennium Ecosystem Assessment (Ecosystems and Human Well-Being: Synthesis, Island Press, Washington DC, 2005). But he goes on to conclude that there is no value in factoring ecosystem services into decision-making, and that indeed they represent a harmful diversion from a more traditional focus on the intrinsic and aesthetic values of nature. We, the assessment panel of the Millennium Ecosystem Assessment, believe that these conclusions result from three errors in reasoning.

First, McCauley assumes that conservation arguments based on ecosystem services are cast only in economic terms. In practice, although it is possible to calculate the economic values of some ecosystem services, this can't be done for others, including many of the cultural services provided by ecosystems. Proponents of ecosystem services argue that it is folly to ignore real economic costs and benefits of decisions. Deliberative decision-making processes are necessary to allow economic, cultural and intrinsic values to be weighed.

Second, McCauley assumes that conservation efforts based on ecosystem services rely only on market-based approaches and hence are always subject to the vagaries of the market. This is not the case. The useful roles played by a watershed in water purification, a woodland for recreation or a forest for carbon sequestration are just some of the many factors used to help convince a government of the merits of protecting certain areas from development. For example, although it would be possible to argue that the coastal wetlands of Louisiana should be protected for their intrinsic value, it is logical - and probably far more effective - to add the utilitarian argument that those wetlands also provide a valuable service in protecting coastal development from storms.

Finally, McCauley assumes that the growing interest in ecosystem services is relevant only to the goal of biodiversity conservation. In practice, scientists, managers and decision-makers are increasingly using the concept of ecosystem services because of its broad usefulness across a wide range of resource-management issues, not just biodiversity protection.

For too long, scientists and managers have tended to view the world as either protected because of the intrinsic or aesthetic value of the area, or developed for its utilitarian benefits. The reality, of course, is that our planet is a mosaic of systems providing people with different bundles of ecosystem services and disservices. We cannot manage these systems effectively if we do not actively seek to measure the flows of these services, examine who is benefiting from them, and consider a range of policies, incentives, technologies and regulations that could encourage better management and sharing of the benefits.

Historically, conservation has largely relied on the considerations of intrinsic value that McCauley sees as the only solution. This has been manifestly insufficient as a response to the increasing threats to biodiversity, particularly in the world's poorest regions, where considerations of intrinsic and spiritual values are often trumped by the needs for survival or used to exclude significant segments of the population from the benefits from their ecosystem resources. It is time to add to the mix other approaches based on a fuller consideration of ecosystem services and options for distributing costs and benefits that may result.

Further information, and details of the signatories, are available at www.maweb.org/ en/about.people.panel.aspx.

Walter V. Reid

Conservation and Science Program, The David and Lucile Packard Foundation, 300 Second Street, Los Altos, Califomia 94022, USA This letter was also signed by: Harold A. Mooney, Doris Capistrano, Stephen R. Carpenter, Kanchan Chopra, Angela Cropper, Partha Dasgupta, Rashid Hassan, Rik Leemans, Robert M. May, Prabhu Pingali, Cristián Samper, RobertScholes, Robert T. Watson, A. H. Zakri, Zhao Shidong.

\section{Nature: ecosystems without commodifying them}

SIR — Douglas J. McCauley, in his Commentary ${ }^{\alpha}$ Selling out on nature" (Nature $443,27-28 ; 2006$ ), suggests that love for nature is incompatible with valuing nature in terms of its contributions to human well-being. But there is no such conflict. Nor is valuation of ecosystem services a panacea; rather, such valuation is one piece of helpful information in the complex task of sustainably managing our natural assets.

Valuing ecosystem services is not identical to commodifying them for trade in private markets. Most ecosystem services are public goods (non-rival and non-excludable), which means that privatization and conventional markets work poorly, if at all. Nevertheless, knowing the value of ecosystem services is helpful for their effective management, which in some cases can include economic incentives, such as those used in Costa Rica's highly successful system of payment for these services (see www.conservation.org/xp/frontlines/ partners/03150604.xml).

It is incorrect to suggest that ecosystemservices reasoning ignores basic ecology; on the contrary, it embraces ecology and the co-dependency of humans and other species. It is also incorrect to suggest that conservation based on protecting ecosystem services is betting against human ingenuity. The study of ecosystem services has merely identified the limitations and costs of 'hard' engineering solutions to problems that in many cases can be more efficiently solved by natural systems. Pointing out that the 'horizontal levees' of coastal marshes are more cost-effective protectors against hurricanes than constructed vertical levees is only using our intelligence and ingenuity, not betting against it.

The ecosystems-services concept makes it abundantly clear that the choice of ${ }^{\alpha}$ the environment versus the economy ${ }^{n}$ is a false choice. If nature contributes significantly to human well-being, then it is a major contributor to the real economy (R. Costanza et al. Nature 387, 253-260; 1997), and the choice becomes how to manage all our assets, including our natural and human-made capital, more effectively and sustainably (R. Costanza et al. BioScience $50,149-155 ; 2000)$.

I do not agree that more progress will be made by appealing to people's hearts rather than their wallets. Ecosystems are critical to our survival and well-being for many reasons - hearts, minds and wallets included. Robert Costanza

Gund Institute of Ecological Economics, Rubenstein School of Environment and Natural Resources, The University of Vermont, 617 Main Street, Burlington 05405, USA

\section{Nature: poorest may see it as their economic rival}

SIR - The moral imperative of saving species and protecting nature, as put forward by Douglas J. McCauley ("Selling out on nature" Nature 443, 27-28; 2006), must be weighed against the moral imperative of saving people. Typically, it is the poorest members of our world community who are most affected by efforts to protect nature, and who suffer the most when ecosystems are degraded.

The conservation debate cannot be reduced to a choice between protecting nature or making an extra million for a yacht or villa. If it were, then perhaps moral arguments alone would be enough to protect the environment. The reality is that poor people are deforesting vast areas of tropical forest for subsistence agriculture, members of indigenous tribes are killing endangered wildlife and out-of-work 
fishermen are converting mangrove forests to shrimp farms. Moreover, biodiversity is greatest in the very areas where human populations are most dense, most rapidly growing and most impoverished (R. P. Cincotta, J. Wisnewski and R. Engelman Nature 404, 990-992; 2000).

McCauley does not acknowledge that economic valuation of ecosystem services can provide the data and tools needed to make human well-being part of the design of conservation projects. Although win-win scenarios are hard to find, it is important that we take the care to quantify ecosystem services, so that those situations in which both humans and biodiversity benefit can be identified and promoted. Moreover, if fundamental economic concepts such as GNP could be reformulated to reflect ecosystem services, then nations might embark on policies that better protect their natural capital assets. The economic valuation of ecosystem services is simply a way of getting everyone's moral imperatives on the same page. It is a way of recognizing that conservation must be accomplished in a just and fair manner, in a way that does not pit the basic needs of humans against nature.

Attention to ecosystem services is not equivalent to venal worship of the dollar. Instead, it provides an entry into market incentives, government policies, betterdesigned conservation projects and a broader constituency for conservation that reaches beyond the affluent Western world.

Conservationists who promote valuation of ecosystem services have no intention of selling out on nature - we just want to make sure it is correctly valued.

Michelle Marvier*, Joy Grantt;, Peter Kareiva †

*Santa Clara University, Santa Clara,

California 95053, USA

†The Nature Conservancy, 4245 North Fairfax Drive, Arlington, Virginia 22203-1606, USA

\section{Nature: McCauley replies}

In my Commentary "Selling out on nature" (Nature 443, 27-28;2006) I argue that ecosystem services can and should be cautiously applied in certain contexts to advance nature conservation. To characterize this discussion as a polarized face-off between proponents of ecosystem services and advocates for nature's inherent values is to have misunderstood my viewpoint. I offer below some responses to specific points raised in criticism of my position.

I concede to anyone wishing to argue that the cultural, historical and aesthetic values of nature can in fact be considered "ecosystem services". This difference seems largely semantic. Call them what you wish, solong as they are made important in conservation.

I cannot agree that the citizens of developing nations are unable to recognize the inherent worth of nature or act to protect it. Many so-called 'poor' cultures have intense legacies of respect for and stewardship of nature. Furthermore, this viewpoint ignores centuries of sacrifice made by severely impoverished people to morally inspired causes such as religion, politics and social movements that did not make them money or directly improve their livelihoods. I simply do not believe that nature is a luxury of the rich.

Although I agree that there is no harm in emphasizing the usefulness of nature, I reassert that there may be harm in overemphasizing this utilitarian worth. The roof of the Sistine Chapel is stunningly beautiful and has much intrinsic value. It also serves to keep the rain out of the church. Pointing out the practical benefits that nature confers will assist conservation so long as these are properly contextualized with and do not harmfully obscure the importance of nature's immense aesthetic worth. Using a diverse approach in conservation will be useful in some circumstances, but in my opinion would notbe as necessary if we worked sufficiently hard in the first instance to educate people about nature's intrinsic value.

My point in writing the Commentary was twofold: first, to encourage a critical review of the strengths and weaknesses of ecosystem services; and second, to more properly articulate an appropriate role for ecosystem services in conservation. I thank the authors of these Correspondence letters for assisting with both tasks.

Douglas J. McCauley is in the Department of Biological Sciences, Stanford University, Stanford, California 94305, USA

\section{Melanoma rates remain high in Australia}

SIR - Your Editorial ${ }^{\text { }}$ Preventing cancer ${ }^{\circ}$ (Nature 442, 720; 2006) is surely incorrect when it argues that because of public-health campaigns melanoma has less of a health impact in Australia than in Britain.

As the populations of Australia and Britain differ, it is necessary to quote rates rather than absolute numbers. If this is done, melanoma mortality is two to three times higher, and incidence rates around four times higher, in Australia than in the United Kingdom. The absolute number of deaths is higher in Britain because more people live in Britain than Australia (see B. Armstrong in Textbook of Melanoma (eds J. F. Thompson, D. L. Morton and B. B. R. Kroon) 65-80; Dunitz, London, 2004).

\section{Jonathan Rees}

Department of Dermatology, Lauriston Building,

University of Edinburgh, Lauriston Place,

Edinburgh EH3 9HA, UK

\section{Getting the public on board for cancer screening}

SIR - Your News Features on cancer
(Nature 442, 735-743; 2006) highlight important developments in research since President Richard Nixon declared war on cancer in 1971. Numerous epidemiological as well as case-control studies have confirmed that early intervention translates into

better survival.

However, when looking at biomarkers DNA or proteins that could indicate pathological processes - it is important to distinguish between those that assess 'risk of cancer' and those that are suitable for screening. In the former, the individual may already be at risk, harbouring a premalignant condition such as adenomatous colonic polyps. Although benign, these polyps have the potential for malignant transformation over time. Screening, on the other hand, aims to detect disease in those who have no symptoms: the smear test, which picks up precancerous changes in the cervical lining, is a successful example.

The public needs to be aware of the differences, otherwise uptake will be low. This is a real problem with breast cancer, for example: uptake of screening is low among women from ethnic minorities, who consequently have higher-than-average rates of breast cancer in both the United Kingdom and the United States

(V. N. Thomas et al. Int. J. Palliat. Nurs. 562, 564-571; 2005, and L. Jandorf et al. Cancer 107, 2043-2051; 2006).

Strategies for the prevention of cancer require biomarkers of early precancerous changes within normal tissue. Ideally, these should be linked to environmental factors that can be modified, such as diet. In colorectal cancer, for example - where $75 \%$ of variance can be explained by diet - the ideal biomarker should reflect differences in dietary exposure. Most people are interested in food and might be prepared to take the recommended action.

The successful test must not only be sensitive and specific for the disease but also appealing to the public; invasive procedures, for example, are less likely to win widespread acceptance. Lessons can be learnt from breast-cancer screening about improving education and awareness. Rightly or wrongly, the success of a screening biomarker is largely driven by public opinion, which is often poorly informed. Thus, the added task for scientists/clinicians is to convince the public of the efficacy and importance of any new biomarker.

Ramesh P. Arasaradnam

Human Nutrition Research Centre, School of Clinical Medical Sciences, University of Newcastle upon Tyne, Newcastle upon Tyne NE2 4HH, UK 